\title{
Outstanding titles
}

\section{PAIGE $\star$ SWIFT}

\section{in wide use}

Elements of Linear Algebra

Used in U.C.L.A., Williams College, Columbia, U. of Pennsylvania, and $U$. of Indiana

For sophomore or junior mathematics, physics, and engineering majors. The theory of finite-dimensional vector spaces, linear transformations, and matrices is presented with geometric applications and numerous illustrations, examples, and exercises. Matrix algebra is given a modern treatment.

BRUNK An Introduction to Mathematical Statistics

A modern treatment of basic concepts in probability and statistics. Presupposes calculus. (over 70 adoptions)

TAYLOR Advanced Calculus

Emphasizes the concepts and principles of analysis, including properties of the real number system which support the theory of limits and continuity. (over 75 adoptions)

\section{ROSENBACH $\star$ WHITMAN $\star$ MESERVE $\star$ WHITMAN}

College Algebra, Fourth Edition

An introductory course with review of elementary algebra and advanced optional work. (over 90 adoptions)

ROSENBACH $\star$ WHITMAN $\star$ MOSKOVITZ

Essentials of Trigonometry, Second Edition with tables

A short course emphasizing core topics. Includes spherical trigonometry, complex numbers, and logarithms.

HAASER $\star$ LASALLE $\star$ SULLIVAN

A Course in Mathematical Analysis

Volume I Introduction to Analysis

Volume 2 Intermediate Analysis (in preparation)

Presents elementary analysis from the point of view of contemporary mathematics. Primarily for science and engineering students.

Ginn and Home offec: Baston

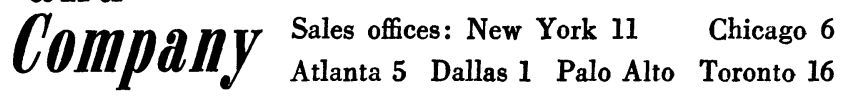




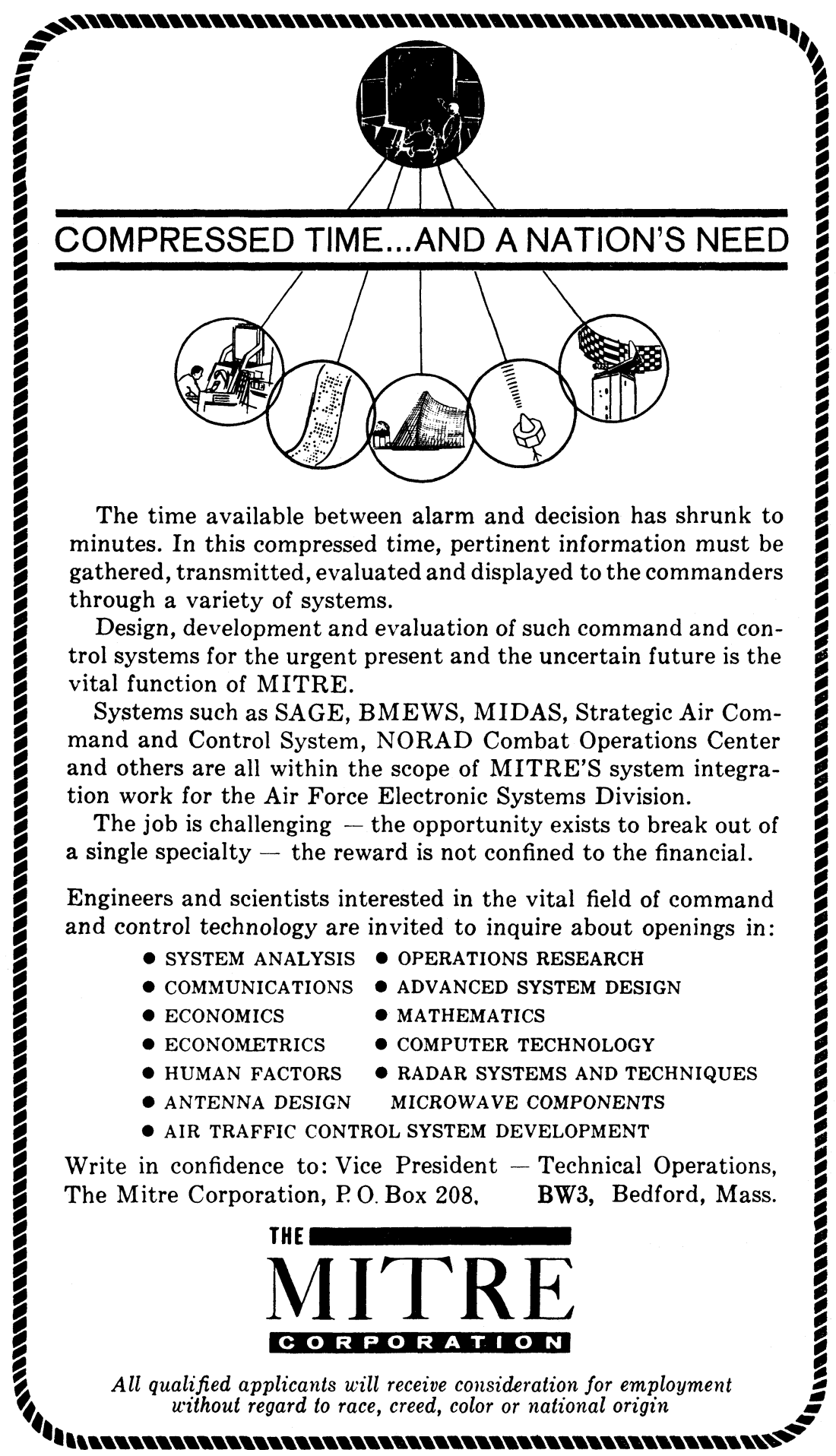




\section{Journals Published by the}

\section{American Mathematical Society}

\section{Bulletin of the American Mathematical Society}

This journal is the official organ of the Society. It reports official acts of the Society and the details of its meetings. It contains some of the officially invited addresses presented before the Society, reviews of advanced mathematical books, research problems and a department of research announcements.

The subscription prize is $\$ 7.00$ per annual volume of six numbers.

Research Problems and Invited Addresses offered by publication should be sent to Walter Rudin, Department of Mathematics, University of Wisconsin, Madison, Wisconsin; Book Reviews to Felix Browder, Department of Mathematics, Massachusetts Institute of Technology, Cambridge 39, Massachusetts. Research Announcements offered for publication should be sent to some member of the Council of the Society, and communicated by him to E. E. Morse, Department of Mathematics, Harvard University, Cambridge 38, Massachusetts. All other communications to the editors should be sent to the Managing Editor, E. E. MoIsE.

The members of the Council for 1961 are: P. T. Bateman, E. G. Begle, Lipman Bers, R. P. Boas, H. W. Bode, H. F. Bohnenblust, Raoul Bott, Felix Browder, R. H. Bruck, R. C. Buck, M. M. Day, Jean Dieudonné, J. L. Doob, A. Erdelyi, G. E. Forsythe, P. R. Garabedian, A. M. Gleason, J. W. Green, P. R. Halmos, G. A. Hedlund, M. R. Hestenes, Edwin Hewitt, Einar Hille, G. P. Hochschild, G. B. Huff, Nathan Jacobson, Michel Loève, E. J. McShane, W. S. Massey, A. E. Meder, Jr., E. E. Moise, Deane Montgomery, L. J. Paige, R. S. Phillips, R. S. Pierce, Everett Pitcher, G. de B. Robinson, Alex Rosenberg, Walter Rudin, I. J. Schoenberg, I. M. Singer, E. H. Spanier, C. B. Tompkins, A. W. Tucker, S. M. Ulam, J. V. Wehausen, J. W. T Youngs, O. Zariski, Daniel Zelinsky, Leo Zippin, Antoni Zygmund.

\section{Proceedings of the American Mathematical Society}

'This journal is devoted entirely to research in pure and applied mathematics and is devoted principally to the publication of original papers of moderate length. A department called Mathematical Pearls was established in 1961. The purpose of this department is to publish very short papers of an unusually elegant and polished character, for which there is normally no other outlet.

The subscription price is $\$ 11.00$ per annual volume of six numbers.

Papers in algebra and number theory should be sent to AlEx RosenBerg, Lunt Building, Northwestern University, Evanston, Illinois; in probability, real variables, logic and foundations to P. R. Halmos, Department of Mathematics, University of Michigan, Ann Arbor, Michigan; in abstract analysis to either P. R. HALmos or Alex Rosenberg; in geometry and topology to E. H. SPANIER, Department of Mathematics, University of California, Berkeley, California; in other branches of analysis, applied mathematics, and all other fields to R. P. BoAs, Lunt Building, Northwestern University, Evanston, Illinois. All other communications to the editors should be addressed to the Managing Editor, P. R. HALmos.

\section{Transactions of the American Mathematical Society}

This journal is devoted entirely to research in pure and applied mathematics, and includes in general longer papers than the ProceEdings.

Four volumes of three numbers each will be published in 1961 . The subscription price is $\$ 8.00$ per volume.

Papers in analysis and applied mathematics should be sent to LIPMAN BERS, Institute of Mathematical Sciences, New York University, New York, New York; in topology to W. S. MASSEx, Department of Mathematics, Yale University, Box 2155, Yale Station, New Haven, Connecticut; in algebra, number theory, and logic to DANIEl Zelinsky, Department of Mathematics, Northwestern University, Evanston, Illinois; in geometry and abstract analysis to I. M. Singer, Department of Mathematics, Massachusetts Institute of Technology, Cambridge 39, Massachusetts; in statistics and probability to Michel Lot̀ve, Statistics Department, University of California, Berkeley, California. All other communications to the editors should be addressed to the Managing Editor, LipMAN BERs. 


\section{Soviet Mathematics-Doklady}

This journal contains the entire pure mathematics section of the DokLADY AKADEMII NAUK SSSR in translation. It appears six times a year, each bimonthly issue corresponding to one volume of the SoviEt DokLaDy. (The DokLaDy AkadEmII Nauk SSSR is issued three times a month, six issues constituting a volume.)

Rates per annual volume are as follows: Domestic subscriptions, $\$ 17.50$; foreign subscriptions, $\$ 20.00$. Single issues are $\$ 5.00$.

\section{Mathematical Reviews}

This journal contains abstracts and reviews of the current mathematical literature of the world. It is sponsored by thirteen mathematical organizations, located both in the United States and abroad.

Mathematical Reviews is published monthly. The subscription price is $\$ 50.00$ per annual volume of twelve numbers. Beginning in 1962, this journal will be published in two volumes. The subscription price of each volume will be $\$ 50.00$.

\section{Notices of the American Mathematical Society}

This journal announces the programs of the meetings of the Society. It carries the abstracts of all contributed papers presented at the meetings of the Society and publishes news items of interest to mathematical scientists. $\$ 2.00$.

The subscription price is $\$ 7.00$ per annual volume of 7 numbers. A single copy is

All communications should be addressed to the Editor G. L. WALkER, 190 Hope Street, Providence 6, Rhode Island. News items and insertions for each issue must be in the hands of the editor on or before the deadline for the abstracts for the papers to be presented in the meetings announced in that issue. These deadlines are published regularly on the back of the title page.

\section{Memoirs of the American Mathematical Society}

This is a series of paperbound research tracts which are of the same general character as papers published in the Transactions. An issue contains either a single monograph or a group of cognate papers. Published at irregular intervals. The latest numbers in this series are:

30. L. Auslander and L. Markus, Flat Lorentz 3-manifolds. 60 pp. 1959

31. W. S. Loud, Periodic solutions of $x^{\prime \prime}+c x^{\prime}+g(x)=\epsilon f(t) .58$ pp. 1959

32. R. S. Pierce, Translation lattices. 66 pp. 1959.

33. Ernst Snapper, Cohomology theory and algebraic correspondences. $96 \mathrm{pp}$. 1959.

34. E. M. Zaustinsky, Spaces with non-symmetric distance. 91 pp. 1959.

35. Richard Bellman and K. L. Cooke, Asymptotic behavior of solutions of differential-difference equations. 91 pp. 1959.

36. Richard S. Palais, The classification of G-spaces. 72 pp. 1960. mappings. 60 pp. 1961

38. R. A. Beaumont and R. S. Pierce, Torsion free groups of rank two. $41 \mathrm{pp}$. 1961. 